\title{
Toxoplasmosis in Indo-Pacific humpbacked dolphins (Sousa chinensis), from Queensland
}

\author{
R O BOWATER ${ }^{a}$, J NORTON ${ }^{a}$, S JOHNSONa, B HILL ${ }^{b}$, P O 'D ONOGHUE ${ }^{c}$ and H PRIOR ${ }^{d}$
}

\begin{abstract}
Objective To describe the clinical signs, gross pathology, serology, bacteriology, histopathology, electron microscopy and immunohistochemistry findings associated with toxoplasmosis in four Indo-Pacific humpbacked dolphins (Sousa chinensis) that stranded in Queensland in 2000 and 2001.
\end{abstract}

Design Clinical assessment, gross necropsy, and laboratory examinations.

Procedure Necropsies were performed on four $S$ chinensis to determine cause of death. Laboratory tests including serology, bacteriology, histopathology and transmission electron microscopy were done on the four dolphins. Immunohistochemistry was done on the brain, heart, liver, lung, spleen and adrenal gland from various dolphins to detect Toxoplasma gondii antigens.

Results Necropsies showed all of four $S$ chinensis that stranded in Queensland in 2000 and 2001 had evidence of predatory shark attack and three were extremely emaciated. Histopathological examinations showed all four dolphins had toxoplasmosis with tissue cysts resembling $T$ gondii in the brain. Tachyzoite stages of $T$ gondii were detected in the lungs, heart, liver, spleen and adrenal gland, variously of all four dolphins. Electron microscopy studies and immunohistochemistry confirmed the tissues cysts were those of $T$ gondii. All four dolphins also had intercurrent disease including pneumonia, three had peritonitis and one had pancreatitis.

Conclusion Four $S$ chinensis necropsied in Queensland in 2000 and 2001 were found to be infected with toxoplasmosis. It is uncertain how these dolphins became infected and further studies are needed to determine how $S$ chinensis acquire toxoplasmosis. All four dolphins stranded after periods of heavy rainfall, and coastal freshwater runoff may be a risk factor for $T$ gondii infection in $S$ chinensis. This disease should be of concern to wildlife managers since $S$ chinensis is a rare species and its numbers appear to be declining. Aust Vet J 2003;81:627-632

$\mathrm{T}$ oxoplasma gondii is a protozoan parasite of worldwide distribution that infects homeothermic animals including primates, marsupials, birds, rodents, other mammals and humans. ${ }^{1,2}$ In Australia T gondii is widespread and has been described from numerous intermediate wildlife hosts including birds such as the southern cassowary, crimson

\footnotetext{
aOonoonba Veterinary Laboratory, Queensland Department of Primary Industries, Animal and Plant Health Service, PO Box 1085, Townsville, Queensland 4810

${ }^{\mathrm{b}}$ Rockhampton Veterinary Laboratory, Queensland Department of Primary Industries, Animal and Plant Health Service, PO Box 6014, Rockhampton Mail Centre, Queensland 4702

${ }^{\mathrm{C}}$ Department of Microbiology and Parasitology, School of Molecular and Microbial Sciences, The University of Queensland, Brisbane, Queensland 4072 dYeerongpilly Veterinary Laboratory, Queensland Department of Primary Industries, Animal and Plant Health Service, 665 Fairfield Road, Yeerongpilly, Queensland 4105
}

rosella, satin bowerbird, domestic pigeon, regent parrot; marsupials such as the koala, common wombat, brown antechinus, kowari, mulgara, and agile wallaby; rodents such as the domestic house mouse and brown rat; and other mammals such as the dingo, domestic dog and cat, sheep and horse. ${ }^{3}$ Toxoplasmosis is rarely reported in marine animals but has been recorded in a west Indian manatee, ${ }^{4}$ a California sea lion, ${ }^{5}$ seals, $, 6,7$ Atlantic bottle-nosed dolphins and a spinner dolphin. 8,9

In 2000 and 2001, five Indo-Pacific humpbacked dolphins (Sousa chinensis), stranded in Townsville, and one stranded in Gladstone. This paper describes toxoplasmosis in four of these dolphins, three from Townsville and one from Gladstone. We describe the findings from necropsy, histological, immunohistochemical and electron microscopic examinations.

\section{M aterials and methods}

Source material

In February 2000, an Indo-Pacific humpbacked dolphin stranded alive in Townsville, Australia (dolphin 1) and was transported by officers of the Q ueensland Parks and W ildlife Service (Q PW S) to a local marine aquarium for rehabilitation, but died 3 days later. In September 2000, another S chinensis was found dead on the bank of a river $40 \mathrm{~km}$ south of Townsville (dolphin 2). The dolphin was reported by members of the public to be rolling from side to side in the water and bumping into boats near a boat ramp, just before its death. In June 2001, a third S chinensis stranded live on the foreshores of Townsville, but died soon after stranding (dolphin 3). In July 2001, a fourth $S$ chinensis was found dead in G ladstone harbour (dolphin 4).

\section{Clinical pathology}

Clinical tests were only possible on dolphin 1 that stranded alive, because all other dolphins stranded dead, or died soon after stranding. Blood was taken from the tail vein of dolphin 1 for a complete blood count and a serum biochemical profile.

\section{Clinical therapy}

Treatment of dolphin 1 included oral antimicrobial therapy with Clavulox palatable tablets (Pfizer, Animal $\mathrm{H}$ ealth Australia) administered via orogastric tubing on day 1. Baytril $150 \mathrm{mg}$ antibacterial tablets (Bayer Australia Ltd) and fluids were thereafter given orally, twice daily. D espite 3 days of such therapy, the dolphin died.

\section{N ecropsy procedure}

All three dolphins that stranded in the Townsville region were necropsied by veterinary pathologists at 0 onoonba Veterinary Laboratory, Townsville, Q ueensland. N ecropsy of the dolphin that stranded in Galdstone harbour (dolphin 4) was done by QPW S officers and tissue specimens were collected and forwarded to Rockhampton Veterinary Laboratory for histological examination. 
H istological preparations and serology

Tissue specimens collected from all four dolphins were fixed in $10 \%$ buffered neutral formalin for $48 \mathrm{~h}$, trimmed and processed routinely for histology. ${ }^{10}$ Sections were cut at $5 \mu \mathrm{m}$ and stained routinely with haematoxylin and eosin for light microscopy. Serum collected from dolphin 1 was tested for T gondii antibody, using an indirect haemagglutination test kit (Laboratoires Fumouze D ivision Diagnostics, Le M alesherbes, France).

\section{Bacteri ology}

Various samples of organs and tissues were taken from dolphins 1, 2 and 3 for bacterial isolation. Samples included the brain, kidney, lung, liver and pericardial fluid from dolphin 1; lung, pancreas and small intestinal contents from dolphin 2; kidney, liver, peritoneal and pleural fluids from dolphin 3.

Transmission electron microscopy

Selected sections of paraffin-embedded brain tissue from all four dolphins were examined by transmission electron microscopy after processing by standard methods. ${ }^{11}$

\section{Immunohistochemistry}

Immunohistochemistry for detection of $\mathrm{T}$ gondii antigens was performed on selected sections of brain (dolphins 1 and 4), liver (dolphins 2 and 4), heart (dolphins 2 and 4), lung (dolphin 4), spleen and adrenal gland (dolphin 3) using a commercial avidin-biotin immuno-peroxidase staining technique (Vectastain Kit; Vector Laboratories Inc, Burlingame, CA). ${ }^{12}$ The primary antibody used was $T$ gondii polyclonal antiserum raised in goats ( $D$ ako C orp, C arpinteria, CA). T he secondary antibody used was an anti-goat serum raised in rabbits (Vector Laboratories Inc). Brain and liver from mice experimentally infected with $T$ gondii were used as positive controls while brains from mice that had been experimentally infected with $\mathrm{N}$ eospora caninum were used as negative controls.

\section{Results}

The locations where the four $S$ chinensis stranded in northern Q ueensland in 2000 and 2001 are illustrated in Figure 1.

\section{Clinical findings and gross necropsy}

Lesions detected at necropsy included superficial, nonpenetrating skin lacerations and wounds consistent with predatory shark attack. All three dolphins that stranded in the Townsville region (dolphins 1 to 3 ) were extremely emaciated, showing prominence of the skull and spine. Dolphin 4, which stranded at G ladstone was in good bodily condition. 0 ther common findings included wart-like skin lesions at the genital opening (dolphins 1, 2 and 4), and the presence of several well-demarcated rounded ulcers ( 0.5 to $1.0 \mathrm{~cm}$ diameter) on the dorsal surface of the tongue and soft palate (dolphins 1, 3 and 4). 0 ther significant clinical and gross necropsy findings for each dolphin are presented below.

\section{Dolphin 1}

The dolphin was an adult female $245 \mathrm{~cm}$ in length and weighed $117 \mathrm{~kg}$. It was dehydrated, weak and ataxic, unable to lift its rostrum above the water line to breathe, and unable to right itself in the water, continually rolling to either side. The right eye showed corneal opacity and the teeth were moderately worn. At necropsy, both lungs were emphysematous with disseminated small caseous nodules more numerous in the

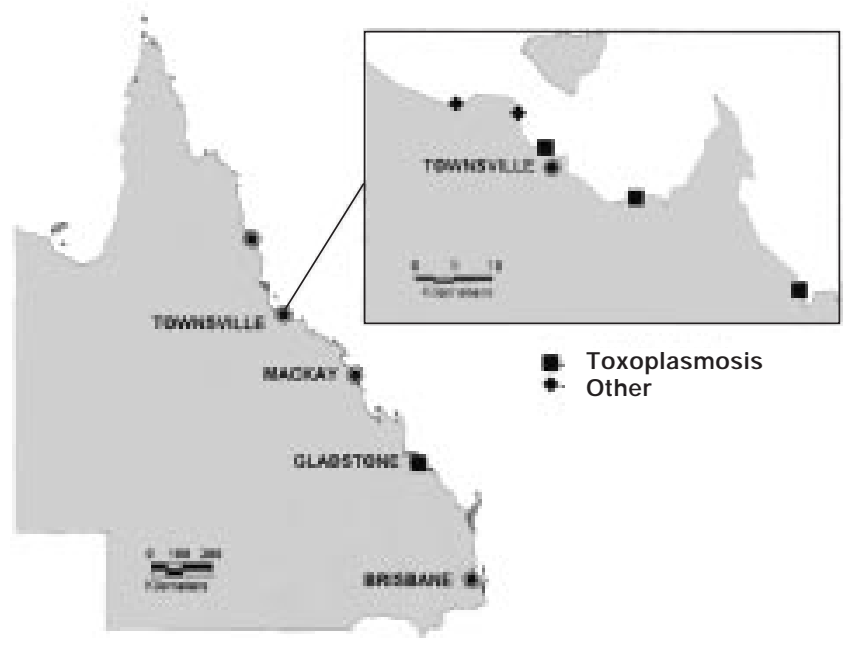

Figure 1. The location of four Sousa chinensis with toxoplasmosis that stranded in northern Queensland in 2000 and 2001.

caudal third of both lung lobes. Fibrin tags adhered to the pleura of the right lung and the bronchial lymph nodes were enlarged. The pancreas was swollen and pal pably hard in several areas, and there was torsion of the omentum at the site of attachment to the proximal duodenum. The mesenteric lymph nodes throughout the abdominal cavity were enlarged.

\section{Dolphin 2}

The dolphin was an adult female, $247 \mathrm{~cm}$ in length. At necropsy, there were fibrin tags adhering to the pleura of both lungs. The mesenteric lymph nodes were enlarged, and the mucosal surfaces of the pyloric region and bile duct were reddened. The stomach was distended and contained remnants of fish bones.

\section{D olphin 3}

The dolphin was an adult female, $232 \mathrm{~cm}$ in length. There was a small straight scar $1 \mathrm{~cm}$ long located mid-ventrally, approximately $60 \mathrm{~cm}$ dorsal to the genital opening that connected by a sinus tract to the abdominal cavity. The mesenteric lymph nodes were enlarged and there was haemorrhagic fibrinous peritonitis. Fibrin adhered to the lining of the abdominal wall where the sinus tract opened into the abdominal cavity, and also to the mesentery, serosa of the stomach, pancreas, liver, right hemi-diaphragm and pleura of the right lung. A stingray barb, $15.2 \mathrm{~cm}$ long was found lodged in the liver, surrounded by fibrous tissue, purulent exudate and fibrin. The stingray spine was identified as belonging to Dasyatis sp ( $P$ Last, personal communication).

\section{Dolphin 4}

This dolphin was a male, $180 \mathrm{~cm}$ in length in good body condition. Gross necropsy findings were reported as unremarkable by Q PW S officers.

\section{Serology}

Dolphin 1 showed significant haematological findings including neutrophilia $\left(19.83 \times 10^{9} / \mathrm{L}\right)$. Serum fibrinogen ranged from $3.6 \mathrm{~g} / \mathrm{L}$ to $4.0 \mathrm{~g} / \mathrm{L}$ over 3 days and was within normal limits. Creatinine kinase rose from $232 \mathrm{U} / \mathrm{L}$ to 1526 $\mathrm{U} / \mathrm{L}$ and lactic acid dehydrogenase from 1575 to $2365 \mathrm{U} / \mathrm{L}$ over 3 days. 


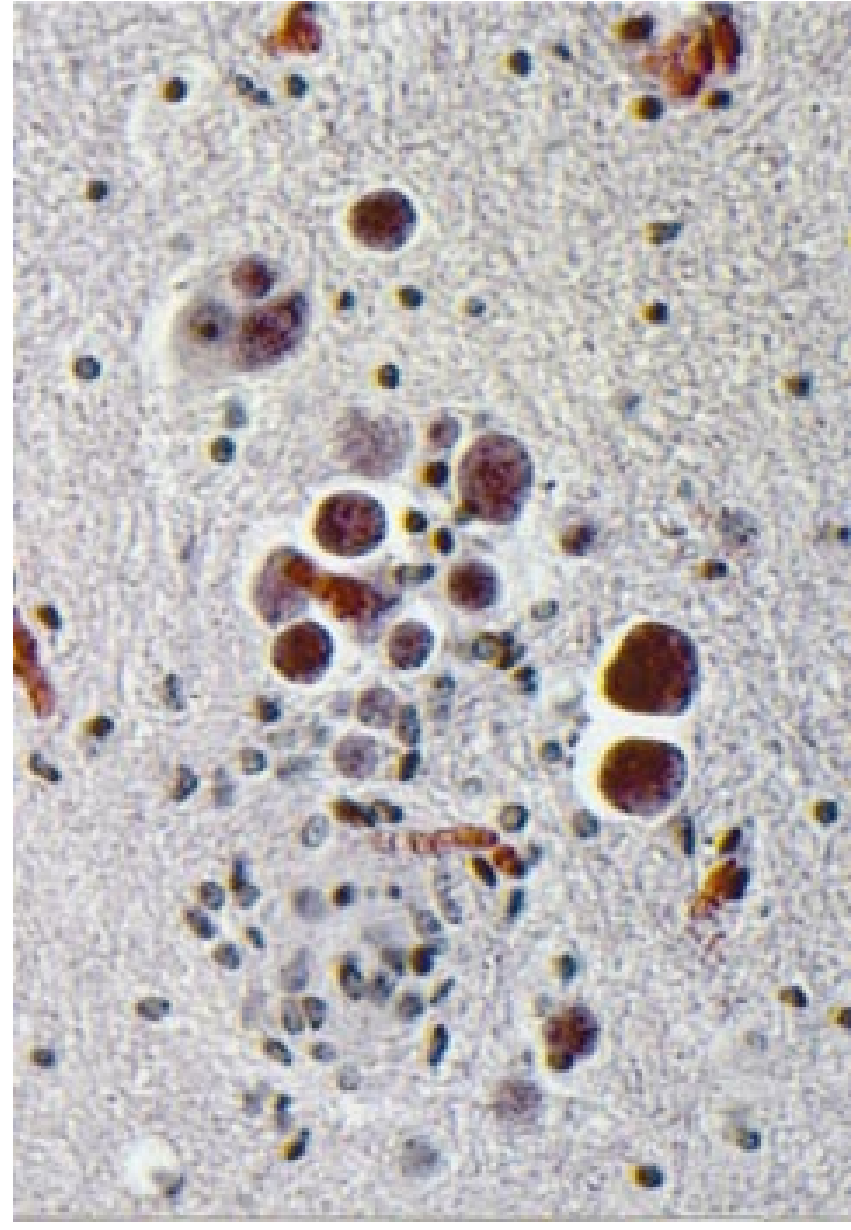

Figure 2. Light micrograph showing numerous Toxoplasma gondii cysts in the brain of Sousa chinensis, associated with gliosis. Haematoxylin and eosin x 300 .

Serum from dolphin 1 tested positive for $\mathrm{T}$ gondii antibody at a dilution of 1 in 2560 .

\section{Bacteriology}

A pure growth of Pseudomonas aeruginosa was isolated from the lungs of dolphins 1 and 2 . A number of bacteria were isolated, variously from the kidney, liver, peritoneal and pleural fluid of dolphin 3 including Clostridium perfringens, Edwardsiella tarda, E hoshinae, Pseudomonas sp, P aeruginosa, Vibrio alginolyticus and $V$ harveyi. The bacteria isolated from dolphin 3 were considered secondary invaders and will not be considered further.

\section{H istopathology}

Significant histopathological findings from all four dolphins are shown in Table 1. The most striking lesions were seen in the brains, where there were large numbers of protozoan cysts, ranging in size from 6 to $30 \mu \mathrm{m}$, scattered throughout the neuropil but mainly in the brain stem and cerebrum with few cysts found in the cerebellum (Figure 2). M any cysts appeared to be fragmenting. Intense infiltrates of mononuclear inflammatory cells, consisting mainly of macrophages and lymphocytes, were often associated with these cysts. There were numerous microglial nodules throughout the brain tissue but these were not always associated with discernible cysts.

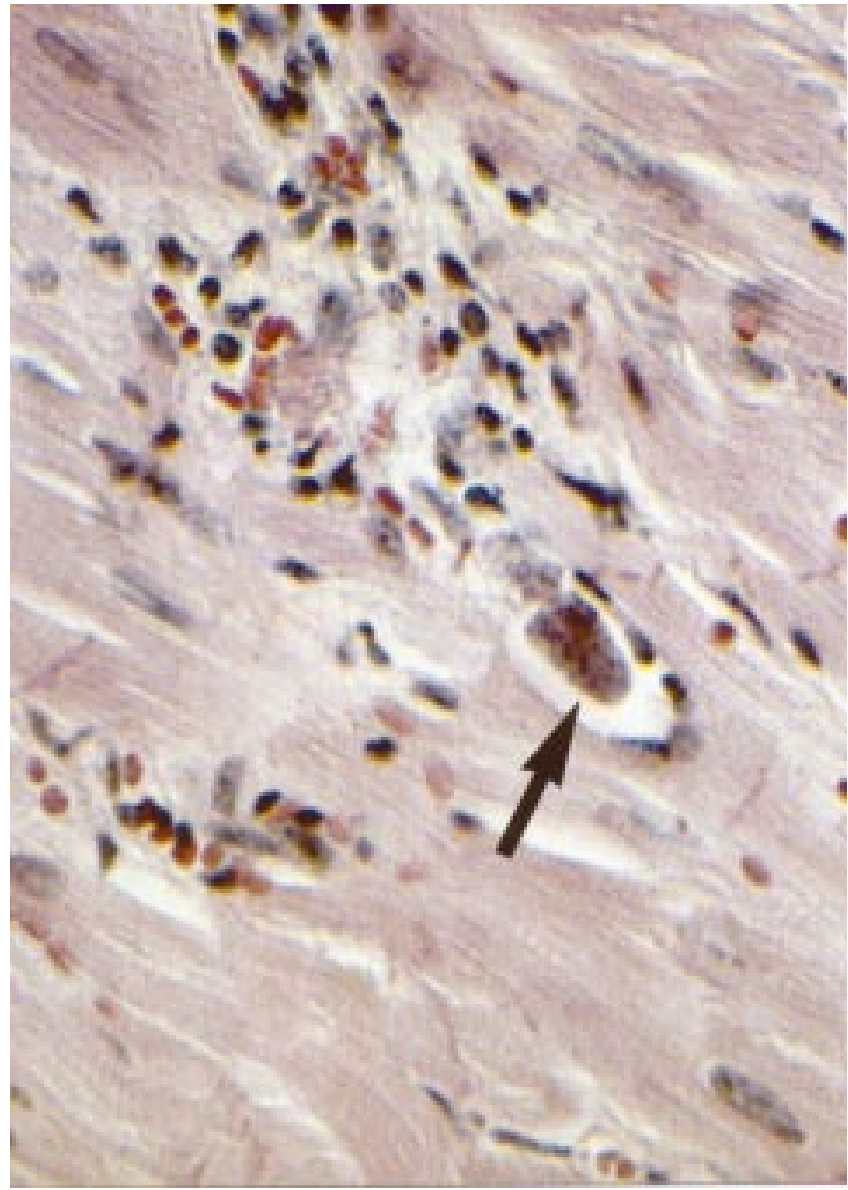

Figure 3. Light micrograph of the heart of Sousa chinensis, showing tachyzoites (arrow) of Toxoplasma gondii within the cardiac muscle. Note the adjacent focus of mononuclear inflammatory cells. $\mathrm{H}$ and $\mathrm{E} \times \mathbf{3 0 0}$.

Perivascular cuffs of mononuclear inflammatory cells were also evident. M ultifocal areas of necrosis were commonly observed and these were similarly infiltrated with mononuclear inflammatory cells.

0 rganisms consistent with tachyzoite stages of $\mathrm{T}$ gondii were also detected histologically in various tissues including the parenchyma of the liver (dolphin 2), the myocardium (dolphins 2 and 4) (Figure 3), the spleen and adrenal gland (dolphin 3).

0 ther histological findings included purulent interstitial and bronchopneumonia (dolphin 1), fibrinous bronchopneumonia (dolphin 2), diffuse fibrinous bronchopneumonia and choroiditis (dolphin 3), and diffuse interstitial pneumonia (dolphin 4).

\section{Immunohistochemistry}

Immunoperoxidase staining performed on selected sections of brain, liver, heart, lung, spleen and adrenal gland from the various dolphins all tested positive and confirmed that suspected tachyzoites present in these organs were those of $T$ gondii (Table 2). The immunoperoxidase staining performed on the brain and liver of mice experimentally infected with $T$ gondii used as positive controls tested positive, whereas brains of mice experimentally infected with $\mathrm{N}$ eospora caninum tested negative. 
Transmission electron microscopy

Examination of the electron micrographs of brain tissue in all cases showed numerous polyzoic cysts within the neural tissue (Figure 4). The cysts were identical in ultrastructure to those of the cyst-forming apicomplexan parasite $T$ gondii. ${ }^{1}$ The cysts were round in cross-section ranging from 20 to $30 \mu \mathrm{m}$ in diameter. They were located intracellularly within enlarged host cells, but the host cell type could not be discerned. The cysts were bounded by a thin membranous wall (up to $40 \mathrm{~nm}$ thick) supported by a granular ground substance. The cyst wall did not contain any protrusions and was surrounded on the external surface by host cell mitochondria and endoplasmic reticulum. The cysts were aseptate and contained up to 70 bradyzoites in cross-section. The bradyzoites were elongate and measured up to $5.2 \mu \mathrm{m}$ in length by $1.7 \mu \mathrm{m}$ in width. They contained a prominent apical complex consisting of an anterior conoid, polar ring, 8 to 10 large rhoptries and 20 to 50 smaller micronemes. The bradyzoites were bounded by a pellicle consisting of two membranes, the inner membrane being discontinuous at the anterior and posterior polar rings and the lateral micropore. The membranes were supported by 22 subpellicular microtubules evident in cross-section. The nucleus was located in the posterior half of the cell body and was closely associated with a mitochondrion and Golgi body. The bradyzoites contained variable amounts of endoplasmic reticulum, some dense granules and occasionally some polysaccharide granules.

\section{Discussion}

O ur findings from histopathological examination of tissues and electron microscopy are similar to other reported cases of toxoplasmosis in marine mammals, in that $\mathrm{T}$ gondii tissue cysts were detected in the brain, and $T$ gondii tachyzoites, in association with focal necrosis, were detected in various other body organs. ${ }^{4-9}$ The electron microscopical findings were consistent with tissue cysts of $T$ gondii and allowed differentiation from other cyst-forming coccidia including Sarcocystis, Frenkelia, Besnoitia, H ammondia and N eospora. The cysts could be differentiated from those of Sarcocystis, Frenkelia and Besnoitia variously by the presence of a thin primary cyst wall, the absence of a secondary cyst wall, the absence of septae and the small size of the zoites. They differed from those of $\mathrm{Hammondia}$ and $\mathrm{N}$ eospora in the small size of the membranous cyst wall and the reduced organelle content of the zoites, especially the number of rhoptries. In each of our four cases we observed large numbers of tissue cysts in the brain, and tachyzoites were observed in at least one other organ including the heart, adrenal gland, spleen and liver. The presence of numerous tissue cysts in the brain in all four dolphins suggested the possibility that these resulted from the reactivation of a chronic infection through the debilitating effect of intercurrent disease. All of the dolphins had intercurrent disease, including pneumonia (all four dolphins), pancreatitis (dolphin 1) and peritonitis (dolphins 1, 3 and 4).
Table 2. Results of $T$ gondii immunohistochemistry from organs of four Sousa chinensis (dolphins 1, 2, 3 and 4) with toxoplasmosis necropsied in Queensland in 2000 and 2001.

\begin{tabular}{lcccc}
\hline Organ & \multicolumn{4}{c}{ Dolphin } \\
\cline { 2 - 5 } & 1 & 2 & 3 & 4 \\
\hline Brain & + & NT & NT & + \\
Heart & NT & + & NT & + \\
Liver & NT & + & NT & + \\
Lung & NT & NT & NT & + \\
Spleen & NT & NT & + & NT \\
Adrenal gland & NT & NT & + & NT
\end{tabular}

$+=$ positive

NT $=$ not tested

Four S chinensis that stranded in northern Q ueensland in 2000 and 2001 had encephalitis attributable to infection with T gondii. Clinical examination was possible in only one of these and it showed clinical signs of ataxia prior to death. The importance of toxoplasmosis in Indo-Pacific humpbacked dolphins is uncertain. This study suggests that the disease should be of concern to wildlife managers since the species is listed as rare under the $\mathrm{N}$ ature Conservation Act 1994. Their numbers appear to be declining, but relatively little is known to date about population sizes, ecology and biology of $S$ chinensis. $13,17,18$

The manner in which these dolphins became infected with $T$ gondii is uncertain. Toxoplasmosis is a parasitic disease that infects only homeothermic animals.1,2 $C$ ats are the only known definitive hosts, ${ }^{1}$ and usually become infected by ingestion of intermediate hosts that are infected with tissue cysts of $T$ gondii. 1,2 Infection in intermediate hosts is by ingestion of food, soil or water that is contaminated with oocysts of T gondii. 1,14-16 Intermediate hosts can also be infected vertically by transplacental transmission of tachyzoites or by ingestion of other intermediate host containing T gondii tissue cysts. ${ }^{1,2}$

Recent studies in the Townsville region have shown that $S$ chinensis feed on a variety of marine and freshwater fish and benthic invertebrates ( $G$ Parra, personal communication). A similar diet of common estuarine and reef fish, and occasionally cephalopods and crustaceans has been found for $\mathrm{S}$ chinensis in South Africa and $\mathrm{H}$ ong Kong. ${ }^{17}$ There is no evidence to date 


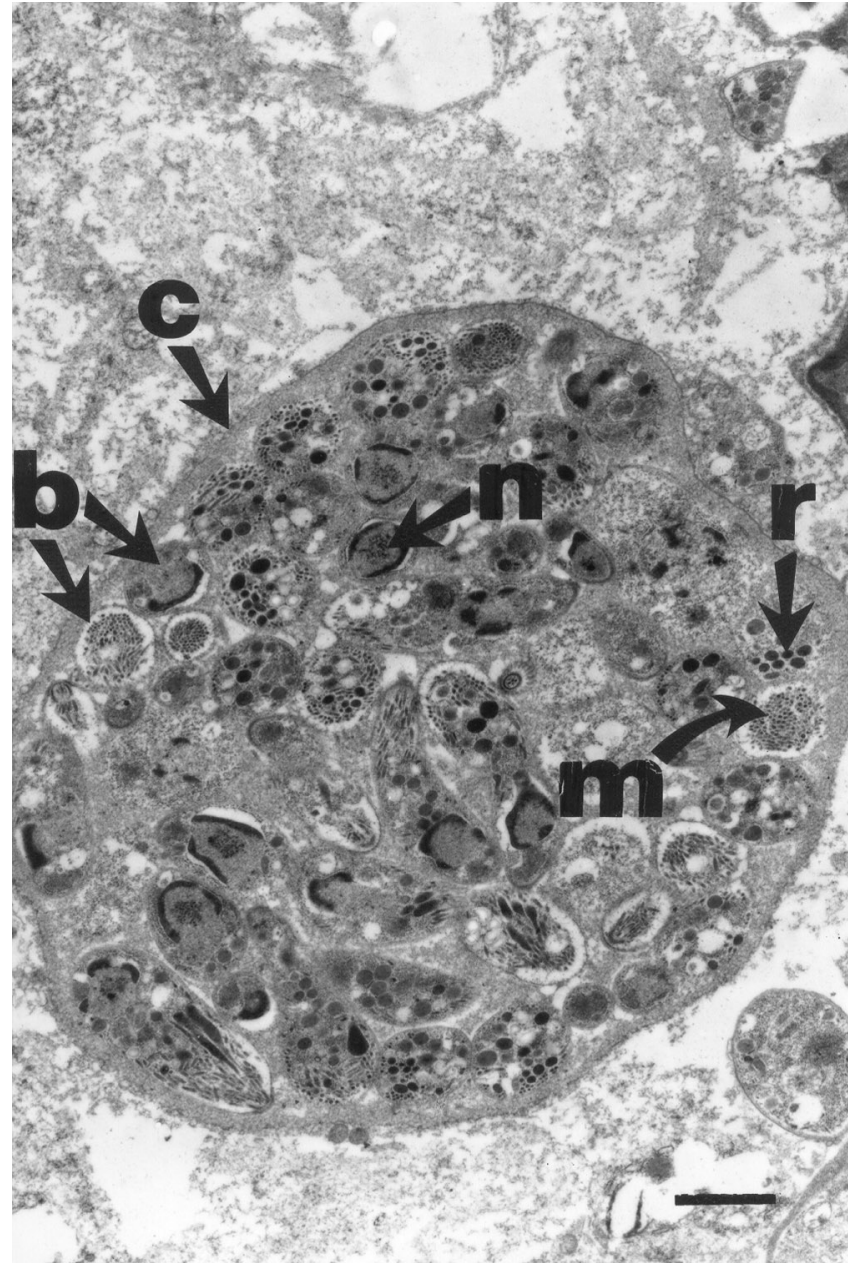

Figure 4. Transmission electron micrograph of an aseptate cyst of Toxoplasma gondii in the brain of Sousa chinensis. The cyst is contained by a membranous cyst wall (c). Within the cyst are numerous bradyzoites (b) in cross section. The bradyzoites are identifiable by their organelles including subterminal nuclei (n), apical rhoptries $(r)$ and apical micronemes $(m)$. Bar $=1.43 \mu \mathrm{m}$.

that $T$ gondii infects poikilothermic animals such as fish or invertebrates. ${ }^{1}$ However it is possible that molluscs or crustaceans may mechanically concentrate $T$ gondii oocysts, acting as vectors for infecting marine mammals such as $S$ chinensis. Lindsay et al recently demonstrated that $T$ gondii oocysts can be removed from seawater by eastern oysters (Crassostrea virginica) and retain their infectivity. ${ }^{19}$ Furthermore if $S$ chinensis occasionally fed upon unusual prey such as wounded or dead seabirds or rodents that were infected with $T$ gondii tissue cysts, then they may incidentally acquire toxoplasmosis.

In Australia $S$ chinensis have a broad geographic distribution yet exhibit some territoriality within inshore coastal areas and do not migrate vast distances throughout their natural range. ${ }^{18}$ Recent studies on the ecology and migration patterns of $S$ chinensis in the Townsville region have shown that they frequent inshore creeks, rivers and coastal areas that are highly urbanised (G Parra, personal communication). Infection with $T$ gondii may thus be acquired locally under specific circumstances. The ingestion during feeding, of water or sediment contaminated with $T$ gondii oocysts is one possible route of infection. It is possible that coastal waters become contaminated with oocysts of $T$ gondii from sewage discharge or floods that carry sediments contaminated with them into creeks and rivers. It may not be coincidental that three infected dolphins stranded in the Townsville region within a year of heavy rainfall and flooding. Miller et al recently reported that coastal freshwater runoff is a risk factor for $T$ gondii infection in southern sea otters (Enhydra lutris nereis) in southern California. ${ }^{20}$ Coastal freshwater runoff may similarly be a risk factor for $T$ gondii infection in $S$ chinensis.

$S$ chinensis may also acquire toxoplasmosis by direct ingestion of infected feline faeces discarded from recreational vessels or from feral cats. In Townsville and Gladstone, feral cats inhabit the rock walls associated with the ports and marinas and domestic cats are kept as pets on board boats and recreational yachts. Domestic cats are also commonly kept as pets in households throughout Townsville and Gladstone, and cat faeces may be discarded into sewers. Although the proportion of infected cats excreting oocysts is generally not high in a given population (less than $2 \%$ in most countries), ${ }^{1}$ a cat may shed millions of oocysts in its faeces and they can remain viable at 15 to $35^{\circ} \mathrm{C}$ for up to 1 year. ${ }^{1}$ Townsville has a tropical climate where the average sea surface water temperatures vary from $24.6^{\circ} \mathrm{C}$ in winter to $29.1^{\circ} \mathrm{C}$ in summer (Australian Oceanographic Data Centre). Townsville sea surface water temperatures favour the long term viability of $T$ gondii oocysts in coastal waters. One of the dolphins that had toxoplasmosis was from Gladstone harbour and was thought to be one of a pod of four to six animals regularly seen at the entrance to Auckland creek and the adjacent marina.

A pilot survey will be conducted on the eastern coast of Queensland to assess the significance of this disease in marine mammals that inhabit marinas and urban coastal areas. This could have implications for the future management of $S$ chinensis, especially pertaining to disposal of domestic cat faeces in marinas and sewage systems in Australia, and for the control of feral cat and rodent populations in coastal regions, especially in marinas and ports.

\section{Acknowledgments}

The authors wish to thank the staff of Oonoonba and Rockhampton Veterinary Laboratories and the QPWS field officers in Townsville and Gladstone, particularly Kim van Stelten, Helen Smith, David Savage, Neil Mattocks, Mark Read, Malcolm Turner and Patrick Centurio for their help in carcase retrieval and specimen collection. Dr Kirstin Dobbs (Great Barrier Reef Marine Park Authority) provided information on the conservation status of $S$ chinensis, and assisted during necropsies, Dr Wendy Blanshard assisted with clinical assessment of dolphin 1, and Bill Doherty assisted with mapping. Veterinary Pathology Services provided serum testing for $T$ gondii. Mr Guido Parra of James Cook University provided valuable information and discussion on population, feeding ecology and behaviour of $S$ chinensis in the Townsville region from his recent studies.

\section{References}

1. Dubey JP, Beattie CP, editors. Toxoplasmosis of animals and man. CRC Press, Boca Raton, Florida, 1988:1-215.

2. Dubey JP, Odening, K. Toxoplasmosis and related infections. In: Samuel WM, Pybus MJ, Kocan AA, editors. Parasitic diseases of wild mammals. 2nd edn. lowa State University Press, Ames, 2001:478-519.

3. O'Donoghue PJ, Adlard RD. Catalogue of protozoan parasites recorded in Australia. Mem Queensl Mus 2000;45:1-163. 
4. Buergelt CD, Bonde RK. Toxoplasmic meningoencephalitis in a West Indian manatee. J Am Vet Med Assoc 1983;183:1294-1296.

5. Migaki G, Allen JF, Casey HW. Toxoplasmosis in a California sea lion (Zalophus californianus). Am J Vet Res 1977;38:135-136.

6. Holshuh HJ, Sherrod AE, Taylor CR, Andrews BF, Howard EB. Toxoplasmosis in a feral northern fur seal. J Am Vet Med Assoc 1985;187:1229-1230.

7. Van Pelt RW, Dieterich RA. Staphylococcal infection and toxoplasmosis in a young harbor seal. J Wildl Dis 1973;9:258-261.

8. Inskeep II W, Gardiner CH, Harris RK, Dubey JP, Goldston RT. Toxoplasmosis in Atlantic bottle-nosed dolphins (Tursiops truncatus). J Wildl Dis 1990;26:377-382.

9. Migaki G, Sawa TR, Dubey JB. Fatal disseminated toxoplasmosis in a spinner dolphin (Stenella longirostris). Vet Pathol 1990;27:463-464.

10. Croft J, Stevens A. Theory and practice of histological techniques. 3rd edn. Churchill Livingstone, London, 1992.

11. Hayat MA. Principles and techniques of electron microscopy. Biol Appl 1970;1:71-273.

12. Naish SJ. Handbook of immunochemical staining methods. Dako, Carpinteria, CA, 1989

13. Species Conservation Team. Great Barrier Reef Marine Park Authority. Supporting document for the whale and dolphin conservation policy. In: Species
Conservation Team. Great Barrier Reef Marine Park Authority, editors. Whale and dolphin conservation in the Great Barrier Reef Marine Park. Great Barrier Reef Marine Park Authority, Townsville, 2000:18-22.

14. Isaac-Renton J, Bowie WR, King A et al. Detection of Toxoplasma gondii oocysts in drinking water. Appl Environ Microbiol 1998;64:2278-2280.

15. Bowie WR, King AS, Werker DH et al. Outbreak of toxoplasmosis associated with municipal drinking water. Lancet 1997;350:173-177.

16. Beneson MW, Takafuji ET, Lemon SM et al. Oocyst-transmitted toxoplasmosis associated with ingestion of contaminated water. New Engl J Med 1982;307:666-669.

17. Jefferson TA, Karczmarski L. Sousa chinensis. Mamm Species, 2001:665: 1-9. 18. Corkeran PJ. Aspects of the behavioural ecology of inshore dolphins Tursiops truncatus and Sousa chinensis in Moreton Bay, Australia. In: Leatherwood S, Reeves, RR. editors. The Bottlenose Dolphin. Academic Press, London, 1990:285-293.

19. Lindsay DS, Phelps KK, Smith SA et al. Removal of Toxoplasma gondii oocysts from seawater by eastern oysters (Crassostrea virginica). J Eukaryot Microbiol 2001;Suppl. S:197-198.

20. Miller MA, Gardner IA, Kreuder C et al. Coastal freshwater runoff is a risk factor for Toxoplasma gondii infection of southern sea otters (Enhydra lutris nereis). Int J Parasitol 2002;32:997-1006.

(Accepted for publication 6 D ecember 2002)

\section{Idiopathic mucosal lesions of the arytenoid cartilages of 21 Thoroughbred yearlings: 1997- 2001}

bnormalities of the upper respiratory tract of Thoroughbred yearlings are commonly identified during pre- or post-sale endoAscopic examination. Some may progress to the detriment of subsequent performance resulting in financial penalty for any purchaser. Published studies of sales examinations make no mention of mucosal lesions of the arytenoid cartilage.

This paper reports results from the post-sale, upper airway endoscopic examinations of 3312 Thoroughbred yearlings during a 5 year period and follows the discovery by the authors of mucosal ulcers and small granulomas on the axial surface of one or both arytenoid cartilages at post-sale endoscopic examination. Mucosal lesions were seen in $0.63 \%$ of the yearlings evaluated and represent the commonest documented abnormal condition of the upper portion of the respiratory tract. At subsequent examination 15 horses had healed without complications. Two horses with bilateral ulceration developed a granuloma at each site, while another developed a granuloma which led to arytenoid chondropathy. One horse was not available for follow up.

The authors conclude that pre-sale endoscopic examination of Thoroughbred yearlings should include careful study of the arytenoid cartilage, particularly at the rostral margin of the vocal process. Medical therapy should be considered and progress monitored. Lesions discovered post-sale warrant notification of the owner and sales company.

Kelly G et al. Equine Vet J 2003;35:276-281.

\section{Medetomidine-ketamine anaesthesia induction followed by medetomidine-propofol in ponies: infusion rates and cardiopulmonary side effects}

olatile anaesthetic agents are commonly employed in equine surgical cases especially in procedures exceeding $1.5 \mathrm{~h}$ duration. A major deficiency of these agents is that they are cardiopulmonary depressants and may result in a high fatality rate, particularly when anaesthesia is maintained for 3-4 $\mathrm{h}$ or more. While several alternatives to inhalational anaesthesia in the horse have been evaluated, the only injectable anaesthetic suitable for long-duration procedures is propofol which requires combination with various $\alpha_{2}$ adrenoreceptor agonists to produce satisfactory depth of anaesthesia. However this regimen presents problems including hypoxaemia, hypercapnia and relatively high costs.

Various propofol/medetomidine combinations of total IV anaesthesia have been used successfully, with good quality of recovery. However inductions were inconsistent and unsatisfactory in some cases.

In this study the anaesthesia of six ponies was induced with medetomidine-ketamine and then maintained with medetomidine-propofol.

Induction is reported as excellent and cardiovascular function remained stable. Recovery to standing after $4 \mathrm{~h}$ of anaesthesia averaged $31.1 \mathrm{~min}$ and was achieved after one or two attempts.

The authors propose this IV regimen as a possible alternative to inhalation anaesthesia with potential to reduce anaesthesiarelated fatality rates in horses.

Bettschart-Wolfensberger R et al. Equine Vet $J$ 2003;3:308-313. 